\title{
Effect of the reducing environment on the accumulation of elastin and collagen in cultured smooth-muscle cells
}

\author{
Peter R. BERGETHON, Peter J. MOGAYZEL, JR. and Carl FRANZBLAU \\ Department of Biochemistry, Boston University School of Medicine, 80 East Concord Street, Boston, MA 02118, U.S.A.
}

\begin{abstract}
We show here that cultured neonatal-rabbit aortic smooth-muscle cells produce and accumulate significant amounts of insoluble elastin. When grown in the presence of ascorbic acid, the amount of insoluble elastin in these cultures decreases, whereas the accumulation of collagen increases. These changes have been attributed to increased hydroxylation of proline in elastin. The function of ascorbic acid in proline hydroxylase, do not demonstrate altered elastin accumulation. These studies are consistent with the molecular iron in the enzyme complex. This study shows that both ascorbic and isoascorbic acids act similarly to modify the accumulation of elastin and collagen in culture. On the other hand, cultures grown in the presence of dithiothreitol, a reducing agent previously shown to act as a cofactor for prolyl hydroxylase, does not demonstrate altered elastin accumulation. These studies are consistent with the suggestion that there is a specific role for ascorbic acid in this cellular system that cannot be replaced by other reducing cofactors.
\end{abstract}

\section{INTRODUCTION}

Elastin is an insoluble polymeric protein that is responsible for the elastic properties of vertebrate tissues. The insoluble elastin fibre is assembled from soluble precursor molecules termed tropoelastin. Though tropoelastin undergoes few post-translational modifications, one of the best characterized is the hydroxylation of 3-8\% of its prolyl residues (Davidson, 1987). The role, if any, of hydroxyproline in tropoelastin is unclear. This is in contrast with hydroxyproline's function in stabilizing the triple-helical confirmation of collagen molecules (Berg \& Prockop, 1973; Uitto \& Prockop, 1974). L-Ascorbic acid is a cofactor for the enzyme prolyl hydroxylase (EC 1.14.11.2), which catalyses the posttranslational hydroxylation of proline in nascent collagen and elastin molecules (Cardinale \& Udenfriend, 1974). In addition, molecular oxygen, ferrous iron and 2-oxoglutarate are necessary cofactors for the normal functioning of prolyl hydroxylase (Adams \& Frank, 1980).

The biochemical activity of ascorbic acid, a 2-oxolactone, is generally considered to reside in the electroactivity of the keto-enol nature of the C-2 and C-3 atoms. D-Ascorbic acid (isoascorbic acid) is an epimer of Lascorbic acid that differs only by the transposition of the $-\mathrm{OH}$ and $-\mathrm{H}$ groups at $\mathrm{C}-5$. Since the electroactivity of both molecules is conferred by the keto-enol portion of the ring, both epimers are essentially equivalent in terms of their oxidation-reduction behaviour (Lewin, 1976).

The role of ascorbic acid in the mechanism of proline hydroxylation is not completely understood, and is still under investigation (Kivirikko \& Myllyla, 1987). Studies in vitro on preparations of prolyl hydroxylase have demonstrated that the requirement for ascorbic acid could be replaced by other agents, including isoascorbic acid, pterins and dithiothreitol (DTT) (Peterkofsky \& Udenfriend, 1965; Hutton et al., 1967; Rhoads et al.,
1967; Rhoads \& Udenfriend, 1970). Later studies with much more highly purified enzyme showed that ascorbic acid was quite specific, though some activity was demonstrated when DTT or L-cysteine was the reductive cofactor (Myllyla et al., 1978). Other investigations have suggested that ascorbic acid plays a non-stoichiometric role in the hydroxylation of proline. Consequently it has been suggested that a possible role for ascorbate may be as a reductant that is not bound to the enzyme (for review see Englard \& Seifter, 1986). However, Majamaa et al. (1986) have provided evidence that a specific binding site for ascorbate exists in prolyl hydroxylase. They also demonstrated that isoascorbic acid binds efficiently to the enzyme, producing similar $V_{\max }$ and $K_{\mathrm{m}}$ values as compared with bound ascorbic acid.

Studies on the effects on the proline hydroxylation in cells cultured in the presence of other reducing agents have variably shown that isoascorbate may (Murad et al., 1981) or may not (Priest \& Bublitz, 1967) replace ascorbic acid. In the latter case, the authors also showed that other agents such as pteridines could be substituted for ascorbate. In addition, Chauhan et al. (1985) have demonstrated that cysteinylcysteine can act as a reducing cofactor in L-929 cells in culture.

Aortic smooth-muscle cells from several species have been shown to produce and accumulate significant amounts of extracellular collagen and elastin when grown in culture (for review see Franzblau \& Faris, 1982). When ascorbic acid is present in these cultures at a concentration of above $0.5 \mu \mathrm{g} / \mathrm{ml}$, the amount of insoluble collagen increases, whereas the content of insoluble elastin decreases (Scott-Burden et al, 1979; DeClerck \& Jones, 1980; Faris et al., 1984). However, the addition of ascorbic acid does not alter the cross-linking profite of the elastin that is accumulated (Dunn \& Franzblau, 1982). Barone et al. (1985) have shown that cultures supplemented with ascorbate produce soluble 
elastin molecules which are overhydroxylated. It is thought that these overhydroxylated molecules do not accommodate the requisite hydrophobic interactions with the growing elastic fibre, leading to decreased elastin accumulation. This study investigates whether the addition of isoascorbate or DTT to cultured neonatal-rabbit smooth-muscle cells leads to increased proline hydroxylation of elastin.

\section{MATERIALS AND METHODS}

\section{Smooth-muscle cell cultures}

Neonatal-rabbit smooth-muscle cells were isolated from aortae of 1-3-day-old New Zealand rabbits as described previously for the neonatal rat (Oakes et al., 1982). Briefly, a collagenase $(10 \mathrm{mg}$; type I, Sigma Chemical Co., St. Louis, MO, U.S.A.)/elastin $(2.5 \mathrm{mg}$; Sigma type III) solution in $20 \mathrm{ml}$ of Dulbecco's modified Eagle's medium without fetal bovine serum (FBS) was added to the medial layer of 20 aortae that were finely minced after careful dissection (Faris et al., 1976). After digestion at $37^{\circ} \mathrm{C}$ for $45 \mathrm{~min}$ the resulting cell suspension was centrifuged at $400 \mathrm{~g}$ for $5 \mathrm{~min}$ and then washed twice with Dulbecco's medium containing $40 \mathrm{~mm}-\mathrm{NaHCO}_{3}$, $20 \%(\mathrm{v} / \mathrm{v}) \mathrm{FBS}, 100 \mu \mathrm{g}$ of penicillin $/ \mathrm{ml}$ and $100 \mu \mathrm{g}$ of streptomycin $/ \mathrm{ml}, \quad 0.1 \mathrm{mM}$ non-essential amino acids (Gibco, Grand Island, NY, U.S.A.) and 1 mM-sodium pyruvate. The cell pellet was then resuspended in fresh medium and seeded at a density of $5.0 \times 10^{5}$ cells $/ 25 \mathrm{~cm}^{2}$ flask (Corning). Cells in primary culture were maintained for 7 days at $37^{\circ} \mathrm{C}$ in a humidified atmosphere of $\mathrm{CO}_{2} / \mathrm{air}$ (1:19). The cells were then subcultivated by trypsin treatment $(0.05 \%$ trypsin $/ 0.02 \%$ EDTA; Gibco) for $5 \mathrm{~min}$ at $37^{\circ} \mathrm{C}$. The cells were reseeded at a density of $1.5 \times 10^{6}$ cells $/ 75 \mathrm{~cm}^{2}$ flask (Corning) or $5 \times 10^{5}$ cells/ $25 \mathrm{~cm}^{2}$ flask and maintained in 20 or $5 \mathrm{ml}$ respectively of medium identical with that described above except that the concentration of FBS was $10 \%$. The medium was changed twice weekly. Cells grown in the presence of ascorbic acid, isoascorbic acid or DTT were supplemented with the respective chemical at $50 \mu \mathrm{g} / \mathrm{ml}$ three times weekly for 4 weeks. For dose/response experiments the supplemental dose was varied $(1,5,10,25$ and $50 \mu \mathrm{g} /$ $\mathrm{ml})$. In all cases, supplementation was initiated on day 6 of the first passage. At no time were primary cultures given reducing supplements. Cells were routinely monitored by phase-contrast microscopy with a Nikon Diaphot inverted microscope. Cell layers were harvested after 2 or 4 weeks in culture.

\section{$\left[{ }^{3} \mathrm{H}\right]$ Proline pulse procedure}

Flasks $\left(25 \mathrm{~cm}^{2}\right)$ used for pulsing experiments were grown in the absence or presence of $50 \mu \mathrm{g}$ of ascorbic acid or DTT $/ \mathrm{ml}$ until the second week of first passage. At the time of pulsing, the medium was aspirated and the cell layer was washed with $2 \times 5 \mathrm{ml}$ of Puck's saline G $\left(\mathrm{Mg}^{2+}\right.$ - and $\mathrm{Ca}^{2+}$-free). For $30 \mathrm{~min}$ before the pulse, the cells were incubated at $37^{\circ} \mathrm{C}$ in $5 \mathrm{ml}$ of proline- and serum-free medium containing ascorbic acid, isoascorbic acid or DTT. This medium was then removed, and the flasks were pulsed with $5 \mathrm{ml}$ of the above media containing $20 \mu \mathrm{Ci}$ of $\left[{ }^{3} \mathrm{H}\right]$ proline $\left(\mathrm{L}-\left[2,3,4,5-{ }^{3} \mathrm{H}\right]\right.$ proline; Amersham; sp. radioactivity $100 \mathrm{Ci} / \mathrm{mmol}) / \mathrm{ml}$. The cells were incubated for 4 or $24 \mathrm{~h}$ at $37^{\circ} \mathrm{C}$, at which time the flasks were harvested. Triplicate flasks were cultured and analysed for each condition.

\section{Determination of elastin, collagen and total protein}

In different experiments from the pulsed cultures, cell layers were analysed at 2 and 4 weeks for the amount of insoluble elastin and collagen in the extracellular matrix. All flasks, whether pulsed or not, were harvested by the following protocol. The media was removed and the cell layers were washed with $2 \times 5 \mathrm{ml}$ of Puck's saline G. Cell layers were harvested with a plastic cell scraper and homogenized in a final volume of $2 \mathrm{ml}$ of water with a motor-driven glass/glass homogenizer. Samples were taken for DNA determination by the diphenylamine method of Burton (1956). Experiments were done in triplicate.

Insoluble elastin was isolated by the method of Lansing et al. (1952). Samples of the cell-layer homogenate were first freeze-dried and then resuspended in $0.1 \mathrm{M}-\mathrm{NaOH}$ at $98{ }^{\circ} \mathrm{C}$ for $45 \mathrm{~min}$. Samples were cooled and then centrifuged at $400 \mathrm{~g}$. The 'Lansing' residues and the supernatants were both acidified to a final concentration of $6 \mathrm{M}-\mathrm{HCl}$ and hydrolysed in vacuo at $110^{\circ} \mathrm{C}$ for $22 \mathrm{~h}$. The hydrolysates were evaporated to dryness under $\mathrm{N}_{2}$, and amino acid analysis was performed as described below. Total protein content was determined by adding the amounts $(\mu \mathrm{mol})$ of amino acids in the supernatant and residue. Collagen content was determined from the hydroxyproline content of the 'Lansing' supernatant.

\section{Amino acid analysis}

Hydrolysates were analysed on a Beckman model 6300 amino acid analyser for amino acid composition. Radioactive hydroxyproline was determined by liquidscintillation counting (LKB RackBeta 1217) after fractionation of the hydrolysates in a Beckman 138 amino acid analyser. Samples were counted for radioactivity.

\section{Purity of ascorbic and isoascorbic acids}

The ascorbic and isoascorbic acids were shown to be without cross-contamination by both melting-point and h.p.l.c. methods. Melting points were determined by the use of a Fisher-Johns melting-point apparatus, and were consistent with those of pure compounds. Both compounds were assayed by h.p.l.c. by a modification of the method of Donner \& Hicks (1981). Briefly, samples were separated by use of an AX-10 (Varian) anion-exchange column by isocratic elution with a mobile phase of acetonitrile/0.05 M- $\mathrm{KH}_{2} \mathrm{PO}_{4}(3: 1, \mathrm{v} / \mathrm{v})$. A Varian model 5000 h.p.l.c. instrument with a u.v. detector reading at $268 \mathrm{~nm}$ was used for these assays. Both compounds showed a single peak on elution and could be separated when mixed. This method is sensitive to amounts of less than $5 \mathrm{ng}$, and, when samples of over 10000 times this amount were separated, no contaminating peak was found. Therefore the materials used were free of crosscontamination, at least to the extent of $0.5 \mathrm{pg}(0.5$ part in $\left.10^{12}\right)$. These free acids were used in all experiments.

\section{Measurement of redox potentials with added ascorbic acid, isoascorbic acid and DTT}

Redox potentials of media with added ascorbic acid, isoascorbic acid or DTT were measured under anaerobic conditions. Dulbecco's modified Eagle's medium with $10 \%$ FBS as described above was deoxygenated by purging with purified $\mathrm{N}_{2}$. The redox potential was measured with a shiny platinum electrode that was 
polished with fine alumina abrasive before experiments. Reference was to a saturated $\mathrm{Ag} / \mathrm{AgCl}$ electrode. All solutions were made in deionized charcoal-filtered water. Water was routinely tested and shown by square-wave voltammetric analysis (EG\&G, PARC, model 273) to be free of trace metals at $<0.1$ p.p.m. Experiments were done with constant stirring at $25^{\circ} \mathrm{C}$. Samples of freshly prepared ascorbic acid, isoascorbic acid or DTT were added, and equilibration was allowed to occur before further portions were added. The $\mathrm{pH}$, which was routinely monitored, remained constant during all titrations.

\section{RESULTS}

The addition of ascorbic acid or isoascorbic acid to the smooth-muscle cell cultures leads to increased deposition of insoluble collagen and decreased contents of insoluble elastin in the extracellular matrices as compared with the unsupplemented control cultures. On the other hand, long-term culture with DTT has no significant effect as compared with controls. Table 1 summarizes the alterations in accumulation of elastin, collagen and total protein as a function of time and cellular growth as assessed by DNA content. Both ascorbic acid and isoascorbic acid affect cell growth slightly, increasing DNA content by 15-20\%. Cells cultured in the presence of DTT had approximately the same DNA content as controls. All cells displayed similar morphology, regardless of the culture conditions. When normalized on a perDNA basis, the total protein accumulation in the cell layers of cultures as determined by amino acid analysis is not significantly different $(P<0.05)$ from that of controls at 4 weeks for all groups and for ascorbic acid and DTT at 2 weeks. There is a slight decrease in normalized totalprotein accumulation in cultures supplemented with isoascorbic acid at 2 weeks as compared with control

Table 1. Effects of ascorbic acid, isoascorbic acid and DTT on total DNA, total protein, elastin and collagen accumulation in 2- and 4week-old neonatal-rabbit aortic smooth-muscle cells.

Each value is the mean \pm S.D. of three flasks.

\begin{tabular}{|c|c|c|c|c|c|c|c|}
\hline Age & Treatment & $\begin{array}{c}\text { DNA } \\
(\mu \mathrm{g} / \text { flask })\end{array}$ & $\begin{array}{c}\text { Total protein } \\
(\mu \mathrm{g} / \mu \mathrm{g} \\
\text { of DNA) }\end{array}$ & $\begin{array}{c}\text { Elastin } \\
(\mu \mathrm{g} / \text { flask })\end{array}$ & $\begin{array}{l}\text { Elastin } \\
\text { (\% of total } \\
\text { protein) }\end{array}$ & $\begin{array}{l}\text { Collagen } \\
(\mu \mathrm{g} / \text { flask })\end{array}$ & $\begin{array}{l}\text { Collagen } \\
\text { (o of total } \\
\text { protein) }\end{array}$ \\
\hline 2 weeks & $\begin{array}{l}\text { Control } \\
\text { Ascorbic acid } \\
\text { Isoascorbic acid } \\
\text { DTT }\end{array}$ & $\begin{array}{l}19 \pm 0.18 \\
24 \pm 0.52 \\
24 \pm 0.24 \\
19 \pm 0.08\end{array}$ & $\begin{array}{r}55.5 \pm 2.04 \\
53.0 \pm 1.11 \\
47.4 \pm 1.48 \\
57.58 \pm 3.25\end{array}$ & $\begin{array}{l}4.25 \pm 1.2 \\
2.69 \pm 0.37 \\
2.49 \pm 0.14 \\
4.81 \pm 1.27\end{array}$ & $\begin{array}{l}7.7 \pm 1.9 \\
5.1 \pm 0.78 \\
5.2 \pm 0.38 \\
8.3 \pm 1.27\end{array}$ & $\begin{array}{l}1.07 \pm 0.01 \\
4.10 \pm 0.17 \\
3.40 \pm 1.73 \\
0.84 \pm 0.09\end{array}$ & $\begin{array}{l}1.9 \pm 0.1 \\
7.7 \pm 0.45 \\
7.2 \pm 0.45 \\
1.5 \pm 0.15\end{array}$ \\
\hline 4 weeks & $\begin{array}{l}\text { Control } \\
\text { Ascorbic acid } \\
\text { Isoascorbic acid } \\
\text { DTT }\end{array}$ & $\begin{array}{r}20 \pm 0.02 \\
23 \pm 0.02 \\
23 \pm 0.03 \\
18.5 \pm 0.03\end{array}$ & $\begin{array}{l}89.67 \pm 9.5 \\
81.46 \pm 5.72 \\
78.10 \pm 5.61 \\
88.67 \pm 1.67\end{array}$ & $\begin{array}{r}11.80 \pm 1.45 \\
5.83 \pm 1.12 \\
6.35 \pm 0.69 \\
15.62 \pm 1.69\end{array}$ & $\begin{array}{r}13.4 \pm 3.2 \\
7.2 \pm 1.65 \\
8.1 \pm 0.81 \\
17.6 \pm 1.85\end{array}$ & $\begin{array}{l}4.88 \pm 0.68 \\
9.57 \pm 0.99 \\
8.71 \pm 1.78 \\
3.12 \pm 0.17\end{array}$ & $\begin{array}{r}5.4 \pm 0.21 \\
11.7 \pm 0.45 \\
11.2 \pm 3.33 \\
3.5 \pm 1.53\end{array}$ \\
\hline
\end{tabular}

Table 2. Amino acid analysis of insoluble elastin ('Lansing' residue)

Representative amino acid analysis of insoluble elastin ('Lansing' residue) extracted from cell layers of 4-week-old neonatalrabbit aortic smooth-muscle cell cultures treated with ascorbic acid, isoascorbic acid or DTT.

\begin{tabular}{|c|c|c|c|c|}
\hline \multirow[b]{2}{*}{ Amino acid } & \multicolumn{4}{|c|}{ Content (residues/1000) } \\
\hline & Control & Ascorbic acid & Isoascorbic acid & DTT \\
\hline Hydroxyproline & 6.6 & 19.1 & 15.1 & 5.4 \\
\hline Aspartic acid & 24.3 & 31.7 & 26.8 & 15.0 \\
\hline Threonine & 22.0 & 22.2 & 20.9 & 12.9 \\
\hline Serine & 27.6 & 29.1 & 27.6 & 19.9 \\
\hline Glutamic acid & 39.3 & 48.0 & 42.0 & 29.0 \\
\hline Proline & 106.9 & 94.3 & 97.0 & 106.1 \\
\hline Glycine & 302.6 & 297.3 & 306.0 & 334.0 \\
\hline Alanine & 220.1 & 206.2 & 215.0 & 238.0 \\
\hline Valine & 70.1 & 66.6 & 68.5 & 59.0 \\
\hline Isoleucine & 17.2 & 17.5 & 17.1 & 19.2 \\
\hline Leucine & 65.4 & 65.5 & 65.5 & 66.1 \\
\hline Tyrosine & 34.2 & 31.1 & 33.0 & 24.6 \\
\hline Phenylalanine & 23.7 & 23.9 & 23.5 & 33.6 \\
\hline Isodesmosine + desmosine & 0.4 & 0.0 & 0.4 & 0.8 \\
\hline Lysine & 9.2 & 12.0 & 10.2 & 8.5 \\
\hline Histidine & 5.7 & 7.1 & 6.4 & 3.7 \\
\hline Arginine & 15.6 & 17.8 & 15.5 & 8.6 \\
\hline Proline + hydroxyproline & 113.5 & 113.6 & 112.1 & 111.5 \\
\hline
\end{tabular}


Table 3. Incorporation of radioactive proline into the insoluble elastin fraction in neonatal-rabbit smooth-muscle cells treated with ascorbic acid, isoascorbic acid and DTT

Cultures were 2 weeks old at time of harvest. Cells were incubated with radioactive proline for $4 \mathrm{~h}$; the media were removed and cells chased for $24 \mathrm{~h}$. Values are expressed as c.p.m. $/ 25 \mathrm{~cm}^{2}$ flask. Each point is the mean \pm S.D of three flasks.

\begin{tabular}{lcccc}
\hline & $\begin{array}{c}10^{-3} \times \text { Total } \\
\text { radioactivity } \\
\text { Treatment }\end{array}$ & $\begin{array}{c}\text { Total elastin } \\
(\mu \mathrm{g} / \text { flask })\end{array}$ & $\begin{array}{c}\text { Elastin sp. } \\
\text { radioactivity } \\
(\text { c.p.m. } / \mu \mathrm{g})\end{array}$ & $\begin{array}{c}\text { Hyp/(Pro+Hyp) } \\
(\%)\end{array}$ \\
\hline Control & $728 \pm 30$ & $1200 \pm 56.6$ & $622 \pm 34.6$ & $0.3 \pm 0.2$ \\
Ascorbic acid & $153 \pm 39$ & $553 \pm 80.3$ & $274 \pm 42.3$ & $11.7 \pm 0.7$ \\
Isoascorbic acid & $254 \pm 33$ & $856 \pm 99.3$ & $296 \pm 14.3$ & $11.9 \pm 0.6$ \\
DTT & $775 \pm 170$ & $1242 \pm 272.2$ & $624 \pm 36.3$ & $0.3 \pm 0.06$
\end{tabular}

cultures. After 2 weeks in culture there is an approx. $40 \%$ decrease in insoluble elastin on a per-DNA basis, and a concurrent $33 \%$ decrease in the proportion of elastin in the cell layer of the isoascorbate- and ascorbatesupplemented cells as compared with control cultures $(P<0.1)$. Coincident with the decrease in insoluble elastin, the amount of collagen per DNA increased 3.8fold when cells were supplemented with ascorbic acid and 3.2-fold with isoascorbic acid. The content of elastin and collagen in the DTT-treated cultures at 2 weeks is essentially unchanged compared to controls. The 4week-old cultures supplemented with either ascorbic acid or isoascorbic acid showed approx. $40 \%$ decreases in the percentage of elastin in the cell layers, with a slightly higher decrease in insoluble-elastin content as compared with unsupplemented control cultures $(P<0.01$ for both). The insoluble-collagen content was increased in these supplemented cultures approx. 2-fold when expressed as a percentage of total protein or on a perDNA basis. In 4-week-old DTT-supplemented cultures there is a slight but significant $(P<0.05)$ increase in the insoluble elastin accumulated and a concurrent decrease in collagen accumulation when compared with control cultures.

Representative amino acid analyses of insoluble elastin ('Lansing' residues) derived from 4-week-old cell cultures grown under each condition is shown in Table 2. There is a significant increase in the hydroxyproline/total proline (proline plus hydroxyproline) ratio in the $\mathrm{D}$ - and L-ascorbic acid-treated cultures. Whereas in the control flasks less than $6 \%$ of the proline residues are hydroxylated, in both of the supplemented cultures the ratio increases to $15-18 \%$. The analysis of the DTT-treated cells is essentially identical with that of the controls. These analyses compare favourably with those for insoluble elastin obtained from intact rabbit aorta (Faris et al., 1976).

The experiments summarized in Table 3 show a dramatic increase in the appearance of radiolabelled hydroxyproline in the insoluble elastin isolated from $\left[{ }^{3} \mathrm{H}\right]$ proline-pulsed cultures grown in the presence of either ascorbic acid or isoascorbic acid. Both the control and DTT-treated cultures had an extent of proline hydroxylation of $0.3 \%$ or less. These radiolabelling studies show a similar proportion of elastin proline hydroxylation in the presence of either ascorbic acid or isoascorbic acid to that seen in the amino acid analyses in Table 2 . Although the absolute percentages of proline hydroxylation in the pulse experiments and the amino acid analyses differ because these are experiments conducted on different sets of neonatal rabbits, the trends in all experiments are always the same. Furthermore, although there is a dramatic increase in radioactive hydroxyproline, there is a concurrent fall in the total radioactivity incorporated into insoluble elastin as compared with controls. Fig. 1 shows that supplementation of cultures with ascorbic acid or isoascorbic acid in the range $1-50 \mu \mathrm{g} / \mathrm{ml}$ shows a maximal effect on hydroxyproline production by $5 \mu \mathrm{g} / \mathrm{ml}$. Cells grown in the presence of DTT experienced a redox environment that was potentiometrically strongly reducing, but these cells showed no increase in hydroxylation of proline over that of the controls.

Fig. 2 shows that as $\mu \mathrm{g} / \mathrm{ml}$ concentrations of ascorbic acid or isoascorbic acid are added to the media, the platinum electrode takes on the potential of these redox couples. A concentration of just $5 \mu \mathrm{g} / \mathrm{ml}$ leads to a fall in the redox potential of the media of $70 \mathrm{mV}$. Fig. 2 also shows the redox properties of media titrated with DTT. These data show that the ability of these compounds to alter the redox potential of the media is

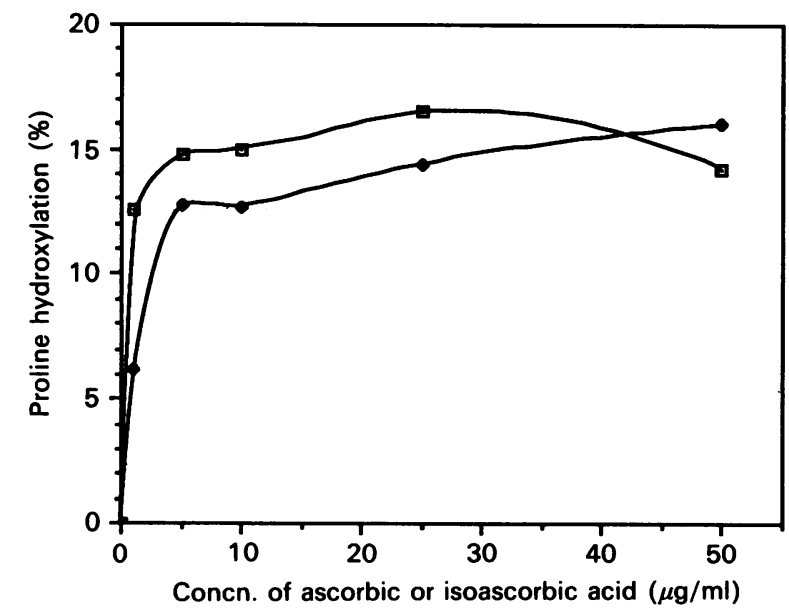

Fig. 1. Dose/response relationship between ascorbic acid and isoascorbic acid and the hydroxylation of proline in insoluble elastin accumulated in 4-week-old neonatalrabbit smooth-muscle cell cultures

Concentration of ascorbic acid ( $\square$ ) or isoascorbic acid $(\diamond)$ is plotted on the abscissa. The ratio of hydroxyproline to total proline, expressed as a percentage, is derived from the amino acid analyses of the 'Lansing' residues of these cultures. Each point is the average of three flasks. 


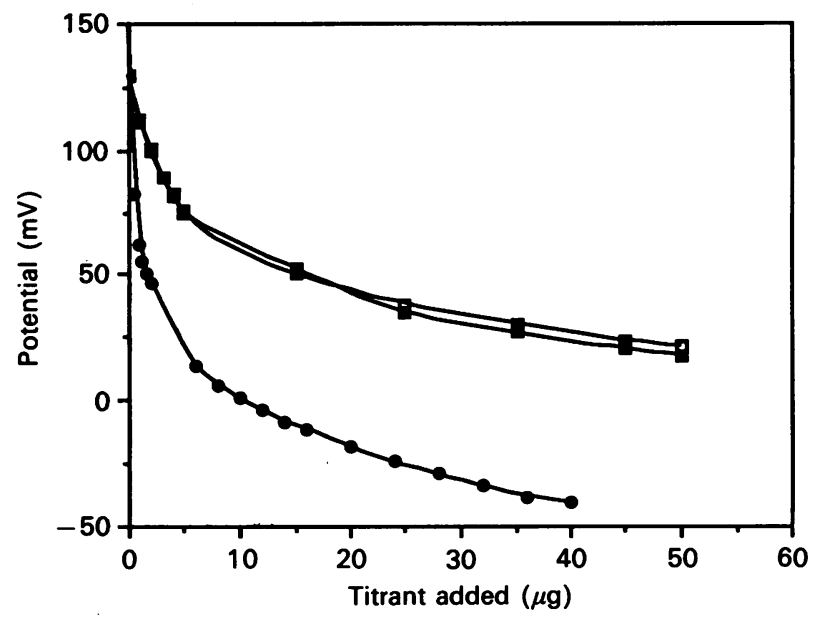

Fig. 2. Potentiometric titration curves for ascorbic acid ( $\square$ ), isoascorbic acid ( $\square$ ) and DTT ( $O$ ) in Dulbecco's modified Eagle's media as described in the text

The concentration of the titrant is plotted on the abscissa. The redox potential at a shiny platinum electrode against a reference of saturated $\mathrm{Ag} / \mathrm{AgCl}$ is expressed in $\mathrm{mV}$ on the ordinate.

dramatic, and furthermore that DTT generates a significant reducing environment, with a fall in potential of nearly $200 \mathrm{mV}$ with the addition of just $2 \mu \mathrm{g}$ of $\mathrm{DTT} / \mathrm{ml}$.

\section{DISCUSSION}

This study clearly shows that the effect of L-ascorbic acid on the accumulation of elastin in the extracellular matrix is not an exclusive property of that isomer. The addition of isoascorbic acid to smooth-muscle cell cultures is almost as effective as ascorbic acid in catalysing the hydroxylation of proline and in increasing insolublecollagen accumulation, with a concurrent decrease in insoluble-elastin accumulation. The experiments with DTT indicate that proline hydroxylation in these cultures does not simply depend on the presence of a reducing environment. Although this result could be explained simply as a failure of the reducing equivalents from DDT to gain intracellular access, we have used Methylene Blue to label cells and follow changes in the intracellular redox environment. When cells are labelled with Methylene Blue, the dye is picked up and the cytoplasm initially stains blue, indicating the oxidized state of the dye. If reducing agents such as 2-mercaptoethanol or DTT are added to the extracellular medium at this point, a reduction of intracellular Methylene Blue occurs, i.e. the dye becomes colourless (results not shown). This would suggest that the extracellular reducing environment can have a dramatic impact on the intracellular environment. Taken together, these data indicate that the general redox potential of the extracellular environment is not responsible for these elastin effects demonstrated here.

Indeed, these studies support the mechanism proposed by Majamaa et al. (1986), suggesting a specific binding requirement for ascorbic acid in the prolyl hydroxylase enzyme. Their evidence that the binding site for the reductant requires the ring atoms, but not the side chains, for binding would suggest that both isoascorbic acid and ascorbic acid could act as equally efficient cofactors. This is consistent with our observations. Since prolyl hydroxylase is an intracellular enzyme, our findings would suggest that in this system both isoascorbic acid and ascorbic acid are effectively transported into the cell, though it may be that this transport favours L-ascorbic acid. It seems reasonable therefore to suggest that the variations reported in the effectiveness of isoascorbic acid in cell culture systems are due to differential transport into the cell, rather than an inability of the isomers to act as cofactors for prolyl hydroxylase.

It is interesting and somewhat surprising that cells grown in long-term culture in the presence of DTT do so well. Cardinale et al. (1975) treated L-929 fibroblasts with $10 \mathrm{~mm}$-DTT for short periods $(1 \mathrm{~h})$ and reported that prolyl hydroxylase activity was abolished, though the amount of immunologically identifiable enzyme increased. Activity could be restored on incubation with ascorbic acid. Our studies are different, in that this DTT treatment was both long-term and utilized a much lower concentration, $300 \mu \mathrm{M}$. The possibility that the lack of hydroxylation found in the cultures incubated with DTT is due to an inactivation of the enzyme cannot be completely excluded. However, when cells were treated simultaneously with $50 \mu \mathrm{g}$ of ascorbic acid $/ \mathrm{ml}$ and $50 \mu \mathrm{g}$ of DTT $/ \mathrm{ml}$ the accumulation of elastin and collagen in the cultures was identical with that of cultures treated with ascorbic acid alone (results not shown). Amino acid analyses of the 'Lansing' residue showed equivalent hydroxylation of proline in the ascorbic acid/DTT and ascorbate-only treated cultures, suggesting that the enzyme was not inactivated. These studies indicate that in this sytem the presence of a strong reducing environment itself is not adequate to account for the effects on hydroxylation of elastin and collagen.

The extensive electrochemical role played by cofactors, both organic and inorganic, in biological systems has been, and will continue to be, an area of intense research. The cell is a complex heterogeneous array of phases, and the behavior of redox couples will be greatly affected by such an environment. Dissecting out the role for a single electroactive species such as ascorbic acid in the midst of this heterogeneous mixture has occupied the attentions of numerous laboratories for many years. This study lends support to the view that it is the specific interaction of the keto-enol ring of the ascorbate molecule in a specific enzymic site that provides the relevant electrochemical activity, rather than a generalized physiochemical effect of the redox environment of the cell.

This study was supported by N.I.H. grants HL-01759 (P. R. B.), HL-19717 and HL-13262. Special thanks are due to Valerie Verbitski, Rosemarie Moscaritolo and George Crombie for their excellent technical assistance. P. J. M. is the recipient of the Charles E. Culpepper Foundation Fellowship.

\section{REFERENCES}

Adams, A. \& Frank, L. (1980) Annu. Rev. Biochem. 49, 1005-1061

Barone, L. M., Faris, B., Chipman, S. D., Toselli, P., Oakes, B. W. \& Franzblau, C. (1985) Biochim. Biophys. Acta 840, 245-254 
Berg, R. A. \& Prockop, D. J. (1973) Biochem. Biophys. Res. Commun. 52, 115-120

Burton, K. (1956) Biochem. J. 62, 315-323

Cardinale, G. \& Udenfriend, S. (1974) Adv. Enzymol. 41, 245-300

Cardinale, G., Stassen, L. H., Kuttan, R. \& Udenfriend, S. (1975) Ann. N.Y. Acad. Sci. 258, 278-287

Chauhan, U., Assad, R. \& Peterkofsky, B. (1985) Biochem. Biophys. Res. Commun. 131, 277-283

Davidson, J. M. (1987) in Connective Tissue Disease: Molecular Pathology of the Extracellular Matrix (Uitto, J. \& Perejda, A. J., eds.), pp. 29-54, Marcel Dekker, New York

DeClerk, Y. A. \& Jones, P. A. (1980) Biochem. J. 186, 217-225

Donner, L. W. \& Hicks, K. B. (1981) Anal. Biochem. 115, 225-230

Dunn, D. M. \& Franzblau, C. (1982) Biochemistry 21, 41954202

Englard, S. \& Seifter, S. (1986) Annu. Rev. Nutr. 6, 365-406

Faris, B., Salcedo, L. L., Cook, V., Johnson, L., Foster, J. A. \& Franzblau, C. (1976) Biochim. Biophys. Acta 418, 93-103

Faris, B., Ferrera, R., Toselli, P., Nambu, J., Gonnerman, W. A. \& Franzblau, C. (1984) Biochim. Biophys. Acta 797, $71-75$

Franzblau, C. \& Faris, B. (1982) Methods Enzymol. 82, 615-637

Hutton, J. J., Jr., Tappel, A. L. \& Udenfriend, S. (1967) Arch. Biochem. Biophys. 118, 231-240

Received 4 July 1988/10 October 1988; accepted 20 October 1988
Kivirikko, K. I. \& Myllyla, R. (1987) Methods Enzymol. 144, 96-114

Lansing, A. I., Rosenthal, T. B., Alex, M. \& Dempsey, E. W. (1952) Anat. Rec. 114, 555-575

Lewin, S. (1976) Vitamin C: Its Molecular Biology and Medical Potential, pp. 5-62, Academic Press, London

Majamaa, K., Gunzler, V., Hanauske-Abel, H. M., Myllyla, R. \& Kivirikko, K. I. (1986) J. Biol. Chem. 261, 7819-7823

Murad, S., Grove, D., Lindberg, K. A., Reynolds, G., Sivarajah, A. \& Pinnell, S. R. (1981) Proc. Natl. Acad. Sci. U.S.A. 78, 2879-2882

Myllyla, R., Kuutti-Savolainen, E.-R. \& Kivirikko, K. I. (1978) Biochem. Biophys. Res. Commun. 83, 441-448

Oakes, B. W., Batty, A. C., Handley, C. J. \& Sanberg, L. B. (1982) Eur. J. Cell Biol. 27, 34-46

Peterkofsky, B. \& Udenfriend, S. (1965) Proc. Natl. Acad. Sci. U.S.A., 53, 335-342

Priest, R. E. \& Bublitz, C. (1967) Lab. Invest. 17, 371-379

Rhoads, R. E. \& Udenfriend, S. (1970) Arch. Biochem. Biophys. 139, 329-339

Rhoads, R. E., Hutton, J. J., Jr. \& Udenfriend, S. (1967) Arch. Biochem. Biophys. 122, 805-807

Scott-Burden, T., Davies, P. J. \& Gevers, W. (1979) Biochem. Biophys. Res. Commun. 91, 739-746

Uitto, J. \& Prockop, D. J. (1974) Biochim. Biophys. Acta 336, 234-251 